\title{
The mediating role of health literacy on the relationship between health care system distrust and vaccine hesitancy during COVID-19 pandemic
}

\author{
Zeynep Turhan $^{1}$ (D) Hacer Yalnız Dilcen ${ }^{2}$ (D) İlknur Dolu $^{3}$ (D) \\ Accepted: 10 July 2021 / Published online: 22 July 2021 \\ (C) The Author(s), under exclusive licence to Springer Science+Business Media, LLC, part of Springer Nature 2021
}

\begin{abstract}
This study explores the mediating role of health literacy on the association between health care system distrust and vaccine hesitancy. An online survey including Personal Information Form, Health Care System Distrust Scale, Vaccine Hesitancy Scale, and Health Literacy Scale were applied to 620 participants. The degree of applying mask-wearing, hygiene rule and physical distance, and the level of COVID-19 vaccine literacy were modeled with hierarchical multiple regression analysis to have a deeper analysis of participants' actions towards COVID-19 vaccine hesitancy. It was found that health care system distrust and health literacy were the most important variables that had an impact on vaccine hesitancy. Based on the mediation analysis, the total effect of health care system distrust on vaccine hesitancy was statistically significant. Participants who held a low level of health literacy and a high perception of the health care system distrust experienced more vaccine hesitancy. The findings suggested the health literacy mediated the relationship between health care system distrust and vaccine hesitancy. Health authorities need to consider the dynamic and complex factors around the health care system distrust and health literacy to reduce vaccine hesitancy during COVID-19.
\end{abstract}

Keywords COVID-19 vaccination $\cdot$ Health communication $\cdot$ Health literacy $\cdot$ Health care system distrust $\cdot$ Vaccine hesitancy

\section{Introduction}

World Health Organization (WHO) Strategic Advisory Group of Experts on immunization stated vaccine hesitancy as a "growing challenge for immunization programs" in August 2015 (WHO, 2015). Vaccine hesitancy also was recognized as an important threat to public health. Several studies paid attention to the relationship between mistrust of the

Zeynep Turhan

zturhan@bartin.edu.tr

Hacer Yalnız Dilcen

hdilcen@bartin.edu.tr

İlknur Dolu

idolu@bartin.edu.tr

1 Department of Social Work, Faculty of Health Science, Bartın University, Ağdacı Campus, Zip code: 74100 Bartin, Turkey

2 Department of Midwifery, Faculty of Health Science, Bartın University, Bartın, Turkey

3 Department of Public Health Nursing, Faculty of Health Science, Bartın University, Bartın, Turkey vaccination programs and the unwillingness to have the COVID-19 vaccine (Bertin et al., 2020; Fadda et al., 2020; Le et al., 2020; Magadmi \& Fatemah, 2020; Palamenghi et al., 2020). Many scholars found a positive role of health care workers and public health authorities on vaccine acceptance during the COVID-19 crisis (Deml et al., 2019; Frank \& Arim, 2020; French et al., 2020). Similarly, researchers noted that public health authorities and governments need to provide rigorous information about vaccines to reduce potential contradictory and mistrust of information about vaccine efficacy and safety (Biasio et al., 2020; Frank \& Arim, 2020; French et al., 2020; Harrison \& Wu, 2020; Li et al., 2020; Rodriguez, 2016; Sherman et al., 2020; Trueblood et al., 2020; Wang et al., 2018). Also, the government and authorities, health care workers had a critical role in shaping individuals' attitudes toward vaccinations (Anand \& Bärnighausen, 2007; Leask et al., 2012; Wang et al., 2018). Moreover, the COVID-19 vaccine, mask-wearing, applying hygiene rules, and physical distance have been key preventions for COVID-19. However, many people might have failed to follow the rules of using masks, applying hygiene rules, and social distance. Therefore, this study examined the relationship between the key preventions (mask-wearing, applying hygiene rules, and physical 
distance) and vaccine hesitancy by recognizing how initial preventative behavior might be interconnected with the COVID-19 vaccination.

Several scholars noted that improving health literacy can play an important role in individuals' choices of engaging in the activities related to their health problems (Deml et al., 2019; Mackert et al., 2013; Meppelink et al., 2019). The literature highlighted the relationship between health literacy and making a decision based on the health care workers' suggestions (Aboumatar et al., 2013; Goggins et al., 2014; Mancuso \& Rincon, 2006; Pati et al., 2010). Importantly, Biasio et al. (2020) found that individuals who had higher vaccine literacy score had more positive attitudes toward COVID-19 vaccination. Therefore, people can develop knowledge around environmental risks by improving health literacy that may protect them from having the disease (Finn \& O'Fallon, 2017). Although the health care workers impact individuals, the perceptions around trustfulness, honesty, and competence of the health care system might influence the preferences of applying health care providers' recommendations (Rose et al., 2004). In our literature review, we found that the mistrust of the vaccination program or health care providers and inadequate information about vaccines were fundamental in recognizing vaccine hesitancy during the COVID-19 pandemic (Turhan et al., 2020a).

While the available literature showed the significant effects of health literacy on vaccination decisions, there was inadequate evidence about how people intend to take COVID-19 vaccination considering their trust in the health care system. Therefore, this research attempted to fill this gap in the literature by recognizing how individuals' inadequate health literacy could play a mediating role in the relationship between health care system distrust and vaccine hesitancy. This mechanism on the relationship between trust to health care authorities, health policy-makers and vaccine hesitancy during the COVID-19 crisis was suggested in the literature (Frank \& Arim, 2020; French et al., 2020; Harrison \& Wu, 2020; Li et al., 2020; Sherman et al., 2020; Trueblood et al., 2020). However, this has not been tested empirically during the time of the COVID-19 pandemic. In recognizing the complex relationship between trust and vaccination, this study investigated the mediating role of health literacy on the relationship between health care system distrust and vaccine hesitancy in the COVID-19 pandemic.

The reasons for mistrust of the vaccine might be about community members' insufficient information about the development of coronavirus vaccines and small or unpopular manufactures' developed vaccine candidates (Fadda et al., 2020; Le et al., 2020). Also, rumors on social media and conspiracy theories often cause misleading information about the COVID-19 vaccines. Exposing conflicting information on the internet can prevent individuals from appropriately evaluating the information of vaccines (Biasio et al., 2020).
Moreover, Dub'e et al. (2014) noted that social, cultural and political environments may influence vaccine hesitancy. Overall, health care system distrust appeared to be a significant factor in increasing vaccine hesitancy during the COVID19 pandemic (Biasio et al., 2020; Fadda et al., 2020; Le et al., 2020; Sun et al., 2020).

Several studies showed that distrust can change with a patient-provider relationship by developing confidence in providers' skills and knowledge (Dawson-Rose et al., 2016; Evans et al., 2019). Importantly, building a COVID-19 vaccination risk communication and community engagement were considered as key recommendations for an effective COVID19 vaccination program (Committee on Equitable Allocation of Vaccine for the Novel Coronavirus, 2020). Similarly, community engagement and social mobilization can improve public trust about vaccination (Revised report of the SAGE Working Group on Vaccine Hesitancy, 2014). Moreover, the vaccine programs should apply evidence-informed risk and health communication, social marketing, and behavioral science techniques to have an equitable allocation of the vaccine (Committee on Equitable Allocation of Vaccine for the Novel Coronavirus, 2020).

While health care system distrust is the most fundamental factor of vaccine hesitancy, distrust is limited to solely explain vaccine hesitancy. One of the potential mediating factors that link distrust and vaccine hesitancy might be health literacy. Health literacy can be considered as a modifiable risk factor of distrust in health. There is limited theory-driven research regarding the mediating role of health literacy in the relationship between health care system distrust and vaccine hesitancy to predict vaccination (Guo et al., 2020; Lorini et al., 2018). Health care system distrust, as a risk factor, can significantly predict more vaccine hesitancy (Biasio et al., 2020; Fadda et al., 2020; Le et al., 2020; Sun et al., 2020), less is known about whether and how health care system distrust increases the individuals' hesitancy.

\section{The Mediating Role of Health Literacy}

The term 'vaccine hesitancy' means the resistance or reluctance to taking vaccination when the vaccine is available (Dubé et al., 2015; Shapiro et al., 2018). The conditions that contribute to vaccine hesitancy are related to the confidence (trust), complacency (the feelings of low perceived risk about vaccine), and convenience (accessibility of vaccine), known as '3C' model" (Revised report of the SAGE Working Group on Vaccine Hesitancy, 2014). Confidence in vaccination is related to the safety and success of the vaccination processes and the systems that provide vaccines (Revised report of the SAGE Working Group on Vaccine Hesitancy, 2014). In the ' $3 \mathrm{C}$ ' model, health care system distrust is one of the factors affecting vaccine hesitancy. The Vaccine Hesitancy Matrix 
has included three categories: "contextual; individual and group; and vaccine/vaccination-specific" issues (Revised report of the SAGE Working Group on Vaccine Hesitancy, 2014: 12). In this matrix, contextual issues include communication and media environment; influential leaders, immunization program gatekeepers and anti-vaccination lobbies, and so on. Moreover, individual and group determinants such as previous vaccination experiences, knowledge, beliefs, health system, and provider-trust are associated with vaccine hesitancy.

According to the Sørensen Integrated Model, health literacy is associated with the individuals' ability and willingness to access and implement health information (Sorensen, 2013). Furthermore, accessing accurate information and understanding the quality of information about health issues require critical evaluation skills (Jarrett et al., 2015a, 2015b; Lorini et al., 2018; Magasi et al., 2009; Nutbeam, 2000). As health communication is interconnected with vaccine acceptance, receiving adequate information about vaccines often increases vaccine uptake (Biasio, 2017; Lorini et al., 2018). According to the literature review by Lorini et al. (2018), health literacy is sometimes a predictor or a mediator for vaccination. Likewise, theoretical frameworks of health literacy show that health literacy frequently affects vaccine hesitancy (Lorini et al., 2018). Specifically, low health literacy skills might cause vaccine hesitancy when people access limited and contradictory information about the vaccine on the internet (Biasio, 2017). However, there is limited evidence for the mediating role of health literacy on the relationship between health care system distrust and vaccine hesitancy.

Levin and Cross (2004) explored how the role of perceived trustworthiness depends on the type of knowledge transfer. They argued that trust mediated the relationship between strong ties and receipt of useful knowledge. Similarly, some scholars noted that providing sufficient evidence related to trusting relationships leads to greater knowledge exchange (Dirks \& Ferrin, 2001; Mayer et al., 1995). When individuals hold a trusting relationship with the source, they were willing to listen to others' knowledge (Carley, 1991; Levin, 1999; Mayer et al., 1995). According to the theoretical framework by Levin and Cross (2004), trust can shape individuals' perceptions of the usefulness of the information they receive. Based on this theory, it would be possible to argue that when people trust the source (e.g., health care workers or system), they are more likely to listen to and follow their suggestions. Similarly, Sorensen (2013) noted that efficient translation of knowledge was based on trustful interactions with health professionals. Within available theories around the relationship between health care system distrust and health literacy during the COVID-19 pandemic, people need to first build a trusting relationship with the health care system or facilitators then they are more likely to open to receive additional or new knowledge. This positive relationship between trust and intention to receive knowledge can improve health literacy. That is to say, health literacy may mediate the effect of health care system distrust on vaccine hesitancy, wherein health care system distrust exerts an impact on vaccine hesitancy through inadequate health literacy.

Overall, people high in distrust, a lower level of health literacy might be associated with vaccine hesitancy. According to the available evidence and theories, we hypothesized that only individuals' health literacy is low, then we can observe the relationship between health care system distrust and vaccine hesitancy. The present study may better prepare health care professionals working with hesitant people who distrust the health care system by providing essential information about the mediating role of health literacy on the relationship between health care system distrust and vaccine hesitancy. This can enhance developing effective vaccine hesitancy communication during the COVID-19 pandemic.

\section{The Goals of the Study}

We propose the following hypotheses and research question to examine the effects of health literacy and health care system distrust on vaccine hesitancy:

- Hypothesis 1: Health care system distrust is positively associated with vaccine hesitancy.

- Hypothesis 2: Health literacy is negatively associated with vaccine hesitancy.

- Hypothesis 3: Health literacy mediates the relationship between health care system distrust and vaccine hesitancy.

- Research Question: Is health care system distrust a predictor of vaccine hesitancy with the mediating role of health literacy?

\section{Method}

\section{Research Procedures}

We used an online survey to explore the mediating role of health literacy on the relationship between health care system distrust and vaccine hesitancy for this cross-sectional study. The study carried out in December 2020 in Turkey. The University Ethics Committee provided ethical approval for this research (2020-SSB-0265). Data was collected via an online survey link from Microsoft Office 365 Forms due to COVID-19 restrictions. The questionnaire could be filled by any devices having internet access such as cellphone, tablets, personal computers. The online questionnaire included a short presentation of the study team, an explanation of the study objective, information on the anonymity and confidentiality of the collected data, and informed consent for attendance. The inclusion criteria included: Accepting to participate in 
the research and being over 18 years old. Individuals were recruited through social media tools (e.g., Instagram, Facebook, WhatsApp, Twitter, etc.) and personal networks. The sample size consisted of 620 individuals aged 18 years old and over. The sample size was convenient for the Structural Equation Model (SEM) path analysis (Fritz \& Mackinnon, 2007). The survey starts with demographical questions such as age, gender, education and etc. After these questions, the survey follows the COVID-19 Preventions and Literacy Questions, the items of three scales including Health Care System Distrust, Vaccine Hesitancy Scale, and Health Literacy Scale.

\section{Measures}

\section{Personal Information Form and COVID-19 Preventions and Literacy Questions}

Data regarding personal information included gender, educational status, income, age, job status, marriage position. After these demographics, six questions regarding COVID-19 were followed. The first question (Q1) was about identifying the risk group status related to the COVID-19 pandemic. Q1 categorized six groups including none, having a chronic disease, being over 65 , being a health care worker, being pregnant or puerperal and other. Questions 2 and 3 were about understanding COVID-19 information and accessing accurate information about COVID-19 vaccine were included respectively. These questions were (Q2) How difficult do you understand when listening to or reading information about the COVID-19 vaccine? (1: no difficulties, 10: too many difficulties), (Q3) How would you rate your level of accessing sufficient and accurate information regarding the decision making of having the COVID-19 vaccine? (1: I can never reach 10: I can get there immediately). To understand the levels of the application of the preventions around three main attitudes were asked: mask-wearing (Q4), hygiene rules $(Q 5)$ and physical distance (Q6). These questions (Q4-Q5-Q6) provided the scale from 1 (less frequently), to 10 (more frequently).

\section{Health Care System Distrust Scale (HCSDS)}

HCSDS was used to measure participants' confidentiality, competence, trustworthiness and mistrust regarding the health care system (e.g., "My medical records are kept private." "People die every day because of mistakes by the health care system"). A shortened version of HCSDS was developed by Rose et al. (2004) ( $\alpha$.75). It includes 10 statements and one dimension. Scale items were prepared in 5-point Likert type ranged from 1 (strongly disagree) to 5 (strongly agree). The scores can be obtained from the scale approach minimum 5 and maximum 45. The validity and reliability of HCSDS in the Turkish language has been adopted by Yeșildal et al.
(2020). Item correlation values of HCSDS and Cronbach's Alpha values were included, and the overall reliability of the scale was 0.79 . As a result of the confirmatory factor analysis conducted within the scope of the Turkish validity and reliability study, it was determined that the index values of the Insecurity in HCSDS showed good fit and acceptable compliance (Yeșildal et al., 2020).

\section{Vaccine Hesitancy Scale (VHS)}

VHS was used to measure general attitudes towards vaccination. Larson et al. (2015) developed VHS to examine vaccine hesitancy and problems regarding vaccination. Shapiro et al. (2018) psychometrically evaluated this scale (lack of confidence $=\alpha .92$; risks $=\alpha .64$ ). Participants were asked to indicate the level of perceptions about the statements such as " New vaccines carry more risks than older vaccines." "I am concerned about serious adverse effects of vaccines." Yalnız Dilcen et al., (2020b) adapted this scale to the Turkish language, which consists of nine items in a 5-point Likert type $(1=$ strongly disagree, $5=$ strongly agree $)$ and has 2 sub-dimensions: "lack of confidence" and "risks". Some items in the scale are reversely coded (between 1 and 7). Cronbach's alpha coefficient for the Turkish form of the scale was calculated as 0.80 (Yalnız Dilcen et al., 2020b). It was found that the subdimension of lack of confidence and the risks of the internal consistency coefficients of the scale was highly reliable. Scores range from 9 to 45 for the total number of sub-groups. Having higher scores indicates the higher vaccine hesitancy.

\section{Health Literacy Scale (HLS)}

Sørensen et al. (2013) developed the European Health Literacy Survey Questionnaire (HLS-EU-Q) includes 47 items. Sørensen et al. (2013) and (Toçi et al., 2013) simplified this scale with 25 items as the HLS. Aras and Bayık Temel (2017) provided the reliability and validity of the HLS in the Turkish language. They found that the Cronbach's Alpha value was .92, and the alpha values of the sub-dimensions were between .62 and .79. It has been illustrated that the scale items of the Turkish form of the HLS are at a reliable level and the factor structure is similar to the original form. Participants rated their health literacy skills on a 5-point scale (1 = I cannot do it / I have no skills / impossible to do, $5=I$ have no difficulties). The 25 -item short form of the HLS includes four subscales; access to information, comprehension of information, appraisal/evaluation, and application/use. Scores range from 25 to 125 for the total number of sub-groups. Having higher scores indicates higher health literacy. 


\section{Statistical Analysis}

Descriptive statistics were provided regarding frequency, percentage, and standard deviation. Pearson's correlation was performed to evaluate the relationship among continuous variables for checking the normal distribution. Spearman's rho was used for data that did not confirm normal distribution. Since all the questions were mandatory in the prepared online survey, there is no missing data in the data. However, four participants' data were excluded because their age was under 18 years old. SPSS 22.0 was used for analysis, and $p \leq 0.05$ was accepted as the level of significance. A Structural Equation Model (SEM) path analysis was carried out to examine the mediating role of health literacy in the relationship between health care system distrust and vaccine hesitancy using AMOS 22.0. We used bootstrapping percentile confidence interval methods to test the significance of the indirect effect of the health care system distrust in vaccine hesitancy through health literacy. The number of bootstrap samples was 5.000 with a $95 \%$ confidence interval.

\section{Results}

Within 620 participants, $66.9 \%$ were female and $33.1 \%$ were male. Age was used as a continuous variable $(M=35.06$, $S D=12.95$ ). $57,6 \%$ of participants were married and $42,4 \%$ were single. Education was collapsed into four categories: (1) primary school graduate $(3.9 \%)$, (2) high school graduate $(8.1 \%)$, (3) college graduate $(68.1 \%)$, and (4) postgraduate or more $(20.0 \%)$. While $57.6 \%$ of participants stated that they were actively working, $42.4 \%$ were not working. The participants' profession was distorted with five job statuses including education and training (35.4\%), health care $(8.5 \%)$, government and public administration (10.2), engineering (4.7\%), others (41.2\%).

After demographic information, risk groups of COVID-19 were categorized as the first question (Q1) related to the COVID-19 personal conditions. $72.3 \%$ of the participants stated that they did not carry any risk in terms of coronavirus. $27.7 \%$ of participants stated that they had in risk groups such as $(14.2 \%)$ having a chronic disease, $(4.0 \%)$ being a health care worker, $(1.5 \%)$ being over 65 years, $(2.1 \%)$ being pregnant or puerperal, and $(6.0 \%)$ having other types of risk conditions. In the Q2, 37.4\% of participants experienced no difficulties in understanding COVID-19 vaccine information by scoring 10 . The highest percentage $21(\%)$ was collapsed in the score of 5 based on their ability to access accurate information around the COVID-19 vaccine. That meant that most people were at the average of accessing sufficient and accurate information regarding the decision-making of having the COVID19 vaccine. The majority of participants perceived a high level (10 points: more frequently) of applying the preventions such as mask-wearing $(Q 4=61.8 \%)$, hygiene rules $(Q 5=61.6 \%)$, and physical distance $(Q 6=40.5 \%)$ based on scoring 10 .

The relationship between the continuous variables examined within the scope of the study is presented in Table 1. It was observed that there was a small significant correlation between vaccine hesitancy and other variables including age $(r=-.14, p<.01)$, COVID-19 literacy $(r=.15, p<.01)$, COVID-19 vaccine literacy $(r=-.27, p<.01)$, mask wearing $(r=.16, p<.01)$, and hygiene rule $(r=.13, p<.01)$, physical distance $(r=-.08, p<.05)$. Also, vaccine hesitancy moderately correlated with the health care system distrust $(r=-.31$, $p<.01)$ and health literacy $(r=.42 ; p<.01)$.

To validate the relationship between vaccine hesitancy and other variables, a hierarchical regression analysis was performed (see Table 2). The independent variables were analyzed in three stages: (1) age, educational status and risk groups, (2) COVID-19 vaccine literacy (Q2 and $Q 3)$ and preventions (e.g., Q4-Q5-Q6; mask wearing-hygiene-physical distance), (3) health care system distrust and health literacy. These variables were added to the model. In the first stage, young people $(b=-.01, \mathrm{SE}=.00$, exp. $[\mathrm{B}]=-0.15, p<.001)$ with low education $(b=-.10, \mathrm{SE}=.04$, exp. $[\mathrm{B}]=-.09$, $p<.05$ ) held more vaccine hesitancy. In the second stage, participants who had difficulties to understand COVID-19 information (Q2) $(b=.03, \mathrm{SE}=.01$, exp. $[\mathrm{B}]=0.10, p<.01)$ were more likely to experience vaccine hesitancy. Participants who were higher level of experiencing less difficulties in accessing sufficient and accurate information regarding the decision making of having COVID-19 vaccine $(Q 3)(b=$ $-.04, \mathrm{SE}=.01$, exp. $[\mathrm{B}]=-0.14, p<.001)$ were less likely to experience vaccine hesitancy. Less frequently implementing mask wearing $(Q 4)(b=-.08, \mathrm{SE}=0.03$, exp. $[\mathrm{B}]=-.19$, $p<.05)$ were more likely to experience vaccine hesitancy. On the other hand, participants who held higher level of applying hygiene rules $(Q 5)(b=.00, \mathrm{SE}=0.3$, exp. $[\mathrm{B}]=.01, \mathrm{p}$ $<.05)$ and physical distance $(Q 6)(b=.01, \mathrm{SE}=0.02$, exp. $[\mathrm{B}]=.03, \mathrm{p}<.05)$ experienced less vaccine hesitancy. In the third stage, participants who held a low level of health literacy $(b=.28, \mathrm{SE}=.06$, exp. $[\mathrm{B}]=0.19, p<.001)$ and a high perception of the health care system distrust $(b=.54, \mathrm{SE}=.06$, exp. $[\mathrm{B}]=0.34, \mathrm{p}<.001)$ experienced more vaccine hesitancy. According to the results of correlation and regression analysis, it would be sated that, health care system distrust and health literacy were the most important variables that have impact on vaccine hesitancy.

Mediation analysis was conducted to examine the mediating role of health literacy on the relationship between the health care system distrust and vaccine hesitancy (see Table 3). The total effect of health care system distrust on vaccine hesitancy was statistically significant $(\beta=.583$; $p<0.001)$. Negative path coefficient and regression coefficient between the health care system distrust and health literacy were added $(\beta=.539 ; p<0.001)$. The indirect effect 
Table 1 Means, Standard Deviation and correlation matrix for continuous variables

\begin{tabular}{|c|c|c|c|c|c|c|c|c|c|c|c|}
\hline Variable & M & $\mathrm{SD}$ & 1 & 2 & 3 & 4 & 5 & 6 & 7 & 8 & 9 \\
\hline 1.Age & 35.6 & 12.946 & & & & & & & & & \\
\hline 2.Education ${ }^{\mathrm{a}}$ & 3.04 & 0.66 & $.033 \mathrm{a}$ & & & & & & & & \\
\hline 3.COVID-19 literacy $(Q 2)$ & 3.23 & 2.539 & .055 & $-.073^{\mathrm{a}}$ & & & & & & & \\
\hline 4.COVID-19 vaccine literacy $(Q 3)$ & 5.66 & 2.756 & $.224 * *$ & $.113^{\mathrm{a}}$ & $-.194 * *$ & & & & & & \\
\hline 5.Mask wearing $(Q 4)^{a}$ & 9.13 & 1.68 & $-.102 * . \mathrm{a}$ & $.035^{\mathrm{a}}$ & $-.169 * * \cdot \mathrm{a}$ & $.158 * * \cdot \mathrm{a}$ & & & & & \\
\hline 6.Hygiene rule $(Q 5)^{a}$ & 9.24 & 1.51 & $-.078^{\mathrm{a}}$ & $.039^{\mathrm{a}}$ & $-.186^{* * \cdot a}$ & $.140 * * . \mathrm{a}$ & $.631^{* * \cdot a}$ & & & & \\
\hline 7.Physical distance $(Q 6)^{a}$ & 8.49 & 1.88 & $.029^{\mathrm{a}}$ & $.059^{\mathrm{a}}$ & $-.099 * a$ & $.151^{* * \cdot a}$ & $.478^{\mathrm{a}}$ & $.500^{* * \cdot \mathrm{a}}$ & & & \\
\hline 8.Health Systems Distrust & 4.33 & 0.48 & .003 & $-.048^{\mathrm{a}}$ & $-.100 *$ & $-.214 * *$ & $-.090^{* \cdot \mathrm{a}}$ & $-.104 * * a$ & $-.043^{\mathrm{a}}$ & & \\
\hline 9.Vaccine Hesitancy & 2.34 & 0.7 & $-.144 * *$ & $-.074^{\mathrm{a}}$ & $.150 * *$ & $-.269 * *$ & $-.162 * * \cdot \mathrm{a}$ & $-.126^{* * \cdot a}$ & $-.082 * a$ & $-.306^{* *}$ & \\
\hline 10.Health Literacy & 2.87 & 0.45 & $-.107 * *$ & $0.37^{\mathrm{a}}$ & $-.362 * *$ & $.293 * *$ & $.248^{* * \cdot a}$ & $.264 * * a$ & $.218^{* * \cdot a}$ & $-.203 * *$ & $.416^{* *}$ \\
\hline
\end{tabular}

$\mathrm{a}=$ Spearman's rho; $* \mathrm{p}<.05 ; * \mathrm{p}<.01$; Strong correlation, between \pm 0.50 and \pm 1 ; Medium correlation, between \pm 0.30 and \pm 0.49 ; Small correlation, below +. 29

(Indirect effect $=.066 ; 95 \%$ CI, .043-.095) between the health care system distrust and vaccine hesitancy was statistically significant. Therefore, health literacy played a mediating role in the relationship between health care system distrust and vaccine hesitancy. The rule of thumb is that VIF is higher than 5 and tolerance is lower than 0.1 indicates multicollinearity (Kim, 2019). Multicollinearity between independent variables was not found in the present study with the variance inflation factor (VIF) values ranged from 1.014 to 3.378 and tolerance values changed between 0.296 and 0.987 . While it was not given as a table, t-test results showed that female participants were more hesitant against vaccination $(t=2.611 ; p=0.009)$ and distrust on health care system $(t=3.341 ; p=0.001)$ than male. Moreover, unemployed $(t=-2.591 ; p=0.010)$ and married participants $(t=-2.578 ; p=0.011)$ were more hesitant than employed ones and single ones, retrospectively.

Figure 1 illustrates the mediation model of health care system distrust $(\mathrm{a}=.539(.11))$ and health literacy $(\mathrm{b}=.122(.02))$ on vaccine hesitancy (Hypothesis 2). Firstly, the perceptions of health literacy were entered. We presented the standard errors in parentheses. The confidence interval was $95 \%$ and the number of bootstrap samples was 5000. The relationship between health care system distrust and vaccine hesitancy was found as $\mathrm{c}=.517(.05)$.

\section{Discussion}

This article aimed to explore the relationship between health care system distrust and vaccine hesitancy by recognizing the mediating role of health literacy. This research carried out SEM path analysis by using AMOS 22.0. We found that the health care system distrust was a significant predictor of vaccine hesitancy. Moreover, the results showed that health literacy mediated the relationship between health care system distrust and vaccine hesitancy. Similarly, available evidence also showed that the influences of mistrust to the health authorities and inadequate information about COVID-19 vaccination on vaccine hesitancy (Frank \& Arim, 2020; French et al., 2020; Harrison \& Wu, 2020; Li et al., 2020; Sherman et al., 2020;

Table 2 Hierarchical multiple regression analysis for vaccine hesitancy

\begin{tabular}{|c|c|c|c|c|c|c|}
\hline \multirow[b]{2}{*}{ Variables } & \multicolumn{2}{|l|}{ Step 1} & \multicolumn{2}{|l|}{ Step 2} & \multicolumn{2}{|l|}{ Step 3} \\
\hline & $ß(\mathrm{SE})$ & $\operatorname{Exp}(B)$ & $\beta(\mathrm{SE})$ & $\operatorname{Exp}(B)$ & $\beta(\mathrm{SE})$ & $\operatorname{Exp}(B)$ \\
\hline Age & $-.01(.00)^{* * * *}$ & -.15 & $-.01(.00)^{* * * *}$ & -.14 & $-.01(.00)^{*}$ & -.12 \\
\hline Education & $-.10(.04)^{*}$ & -.09 & $-.08(.04)$ & -.07 & $-.08(.04)^{*}$ & -.08 \\
\hline COVID-19 literacy (Q2) & & & $.03(.01)^{* *}$ & .10 & $.01(.01)$ & .04 \\
\hline COVID-19 vaccine literacy (Q3) & & & $-.04(.01)^{* * *}$ & -.14 & $-.01(.01)$ & -.03 \\
\hline Mask wearing (Q4) & & & $-.08(0.03)^{*}$ & -.19 & $-.06(.03)^{*}$ & -.15 \\
\hline Hygiene rule (Q5) & & & $.00(.03)$ & .01 & $.01(0.03)$ & .02 \\
\hline Physical distance (Q6) & & & $.01(0.02)$ & .03 & $.01(.02)$ & .02 \\
\hline Health Literacy & & & & & $-.28(.06)^{* * *}$ & -.19 \\
\hline Health Systems Distrust & & & & & $.54(.06)^{* * * *}$ & .34 \\
\hline $\mathrm{R}^{2}$ & 0.03 & & 0.10 & & 0.26 & \\
\hline $\mathrm{R}^{2}$ change & & & 0.07 & & 0.16 & \\
\hline F change & 9.13 & & 7.80 & & 65.81 & \\
\hline
\end{tabular}


Table 3 The mediating role of health literacy on the impact of the relationship between health system distrust and vaccine hesitancy

\begin{tabular}{|c|c|c|c|c|}
\hline & \multicolumn{2}{|c|}{ Health Literacy } & \multicolumn{2}{|c|}{ Vaccine Hesitancy } \\
\hline & $\beta$ & SE & $\beta$ & $\mathrm{SE}$ \\
\hline Health System Distrust (c way) & & & .583 & .051 \\
\hline $\mathrm{R}^{2}$ & & & .173 & \\
\hline Health System Distrust (a way) & -.539 & .105 & & \\
\hline $\mathrm{R}^{2}$ & .041 & & & \\
\hline Health System Distrust (c way) & & & .517 & .051 \\
\hline Health literacy (b way) & & & -.122 & .019 \\
\hline $\mathrm{R}^{2}$ & & & .224 & \\
\hline Indirect effect & & & $.066^{*}$ & $43-0.095)$ \\
\hline
\end{tabular}

Trueblood et al., 2020). Based on our results, mistrust of health care systems was partially determinant of health literacy and that health literacy mediated the relationship between health care system distrust and vaccine hesitancy. This finding showed that health literacy can be considered as a modifiable risk factor of distrust in health. Importantly, enhancing the level of health literacy in the population with low health literacy and building trust with health care authorities regarding COVID-19 vaccination may reduce the number of hesitant people. Moreover, Stormacq et al. (2019) found how disadvantaged social and socio-economic conditions contributed to low health literacy levels. Therefore, health care authorities should pay attention to improve health literacy among individuals who are in disadvantaged social and economic conditions with low health literacy.

This research examined the relationship between vaccine hesitancy and the preventions of mask-wearing, hygiene rule and physical distance in the COVID-19 crisis. The results showed that while the majority of participants were able to follow the rules such as mask-wearing and hygiene rules, keeping the physical distance for some participants were not applicable. This might be about the uncontrollable environmental issues around physical distance in social life. According to findings of the current study, participants who held less level of implementing mask-wearing were more likely to experience vaccine hesitancy. This finding illustrated that the participants who were less likely to implement maskwearing held more vaccine hesitancy. Furthermore, we found a strong relationship between health literacy and preventions of mask-wearing, hygiene rules, and physical distance maskwearing. Applying these preventions might provide adequate evidence regarding the importance of applying these preventions during the COVID-19 pandemic. Similarly, AsadiPooya et al. (2021) found a relationship between lower education and mask-wearing hesitancy. Furthermore, this present research highlighted how COVID-19 preventions of applying mask-hygiene-physical distance in daily life and the choices of taking vaccination have been interconnected with health care system distrust and health literacy.

This research recommended that the health care system can take actions to improve trust by providing accurate and sufficient information about the COVID-19 vaccination. Likewise, French et al. (2020) provided guidelines for vaccination and strategies for building trust with the government as well as public health authorities. This guideline was set out for governments to encourage them to improve the public knowledge around the COVID-19 vaccination processes. These practices included the plans for behavioral change, the characteristics of the audience, analysis of actions, mobilization, building trust in the vaccine, accessible vaccination and outreach strategies (French et al., 2020). Importantly, to have an effective technique to reduce vaccine hesitancy, scholars from interdisciplinary fields (e.g., sociologists, psychologists, anthropologists, and experts in social marketing, and health communication) should work together (Revised report of the SAGE Working Group on Vaccine Hesitancy, 2014). Developing key strategies might help the authorities to increase individuals' engagement in taking future vaccine when it is available. Therefore, identifying the relationship between distrust in the
Fig. 1 Mediation model of health literacy and health system distrust on vaccine hesitancy

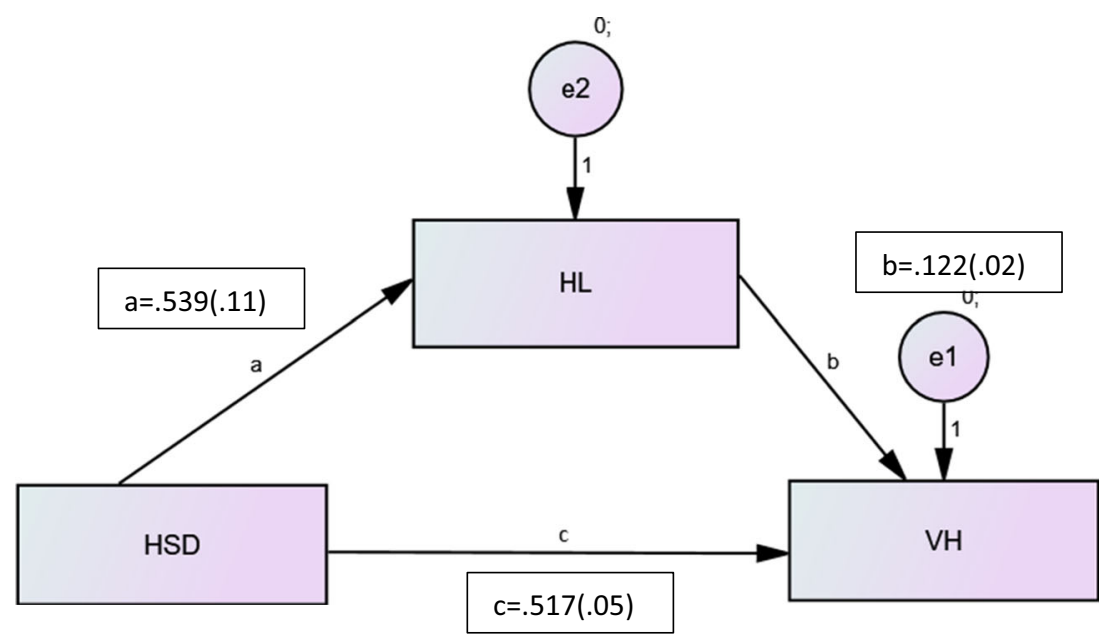


health system and vaccine hesitancy with the mediating role of health literacy can help us develop efficient strategies to increase public confidence in the COVID-19 vaccination.

According to the hierarchical regression analysis, many participants experienced fewer difficulties in understanding COVID-19 vaccine information by scoring themselves 10 points. However, a few participants rated a high degree of difficulty in accessing sufficient and accurate information regarding the decision-making of the COVID-19 vaccination. In hierarchical multiple regression analysis for vaccine hesitancy analyses, participants who experienced more difficulties in accessing accurate information around the COVID-19 vaccine held a higher level of vaccine hesitancy. On the other hand, if participants felt that they immediately achieved the information about the COVID-19 vaccine information regarding the decision-making of taking vaccination, they held less vaccine hesitancy. This result is consistent with the previous research, for example, Biasio et al. (2020) claimed that positive views about COVID-19 vaccination were associated with their vaccine literacy. It would be argued that COVID-19 vaccine literacy is critical for individuals' COVID-19 vaccine hesitancy.

Overall, our findings suggested that community engagement for transferring accurate knowledge about vaccines and trust-building with health authorities as well as the health care system should be implemented as key interventions for hesitant groups during the COVID-19 pandemic. These interventions could include dialogue-based approaches such as social mobilization, engagement with community leaders, and trusted community representatives (Karras et al., 2019; Rodriguez, 2016). When public health authorities and policymakers considered trust issues of vaccination by hearing public concerns, they can take action for this issue (Revised report of the SAGE Working Group on Vaccine Hesitancy, 2014). In this approach, people can make a decision about vaccination related to the best protection for themselves and their family members. Considering the results of recent changes in real-world circumstances, vaccine hesitancy is an important issue in preventing disease. While this article found how health literacy played a mediating role in understanding the relationship between health care system distrust and vaccine hesitancy, complex and dynamic vaccination and public communications should be taken into account to improve individuals' confidence in the vaccination processes.

\section{Limitations}

This research should be evaluated with its limitations. First, this was a one-time survey and the COVID-19 vaccine has just produced during the time of the data collection. Therefore, people might have held more vaccine hesitancy due to new and complex pandemic conditions. Our findings showed that the health care system distrust with the mediating role of health literacy partially explained vaccine hesitancy. This means that other variables also influenced individuals' vaccine hesitancy since multifaceted conditions can shape hesitant groups. Another limitation of this research was that the number of college graduate participants $(88.1 \%)$ was higher than other groups which prevented representing other groups. Using online surveys was a barrier to access people without Internet access. It limited the representation of this group.

\section{Conclusion}

To our knowledge, no research has empirically tested the mechanisms that health literacy influences the relationship between health care system distrust towards vaccine hesitancy during COVID-19 pandemic. It was found that both health care system distrust and health literacy played an important role in the level of vaccine hesitancy. Importantly, a higher level of difficulties around the COVID-19 vaccine literacy regarding decision making of taking vaccine was impacted on increasing vaccine hesitancy. Therefore, health communication practitioners and health system authorities need to recognize the mechanism of health care system distrust, health literacy, and vaccine hesitancy. When this issue is critically considered, it might be possible to reduce vaccine hesitancy by improving trust to the health care system and developing public health literacy.

Acknowledgements Many thanks to the individuals who were volunteer to participate in this research as the topics around COVID-19 vaccine was very stressful during time of data collection.

Authors' Contributions Study conception and design: Zeynep Turhan. Data collection: Zeynep Turhan; Hacer Yalnız Dilcen. Data analysis and interpretation: Zeynep Turhan; İlknur Dolu. Drafting of the article: Zeynep Turhan; Hacer Yalnız Dilcen. Critical revision of the article: Zeynep Turhan, İlknur Dolu.

Funding Not applicable.

Data Availability The datasets generated during and/or analyzed during the current study are available from the corresponding author on reasonable request.

\section{Declarations}

Conflict of Interest The authors have no conflicts of interest relevant to this article.

Ethics Approval The study was reviewed and approved by the Ethics Committee of the Bartın University.

Consent for Publication Informed consents were obtained from participants at the beginning of the survey. The online questionnaire began with brief information about the study objective, by highlighting the anonymity and confidentiality of the collected data, the research team, and informed consent. 


\section{References}

Aboumatar, H. J., Carson, K. A., Beach, M. C., Roter, D. L., \& Cooper, L. A. (2013). The impact of health literacy on desire for participation in healthcare, medical visit communication, and patient reported outcomes among patients with hypertension. Journal of General Internal Medicine, 28(11), 1469-1476. https://doi.org/10.1007/ s11606-013-2466-5.

Anand, S., \& Bärnighausen, T. (2007). Health workers and vaccination coverage in developing countries: An econometric analysis. Lancet, 369(9569), 1277-1285. https://doi.org/10.1016/S0140-6736(07) 60599-6.

Aras, Z., \& Bayık Temel, A. (2017). Sağlık Okuryazarlığı Ölçeğinin Türkçe Formunun Geçerlilik Ve Güvenirliğinin Değerlendirilmesi (Evaluation of the validity and reliability of the Turkish form of the health literacy scale). Florence Nightingale Hemssirelik Dergisi, 25(2), 85. https://doi.org/10.17672/fnhd.94626.

Asadi-Pooya, A. A., Nezafat, A., Sadeghian, S., Shahisavandi, M., Nabavizadeh, S. A., \& Barzegar, Z. (2021). Mask wearing hesitancy during the COVID-19 pandemic in South Iran. Disaster Medicine and Public Health Preparedness, 1-12. https://doi.org/10.1017/ dmp.2021.72.

Bertin, P., Nera, K., \& Delouvée, S. (2020). Conspiracy beliefs, chloroquine, and the rejection of vaccination: A conceptual replicationextension in the COVID-19 pandemic context. Preprint. https:// doi.org/10.31234/osf.io/rz78k

Biasio, L. R. (2017). Vaccine hesitancy and vaccine literacy. Human Vaccines and Immunotherapeutics, 13(3). https://doi.org/10.1080/ 21645515.2016.1243633.

Biasio, R. L., Bonaccorsi, G., Lorini, C., \& Pecorelli, S. (2020). Assessing COVID-19 vaccine literacy: A preliminary online survey. Preprint, July, 1-14. https://doi.org/10.20944/preprints202007. 0295.v1.

Carley, K. (1991). A theory of group stability. American Sociological Review, 56, 331-354.

Committee on Equitable Allocation of Vaccine for the Novel Coronavirus. (2020). Framework for Equitable Allocation of COVID-19 Vaccine. https://doi.org/10.17226/25914.

Dawson-Rose, C., Cuca, Y. P., Webel, A. R., Solís Báez, S. S., Holzemer, W. L., Rivero-Méndez, M., Sanzero Eller, L., Reid, P., Johnson, M. O., Kemppainen, J., Reyes, D., Nokes, K., Nicholas, P. K., Matshediso, E., Mogobe, K. D., Sabone, M. B., Ntsayagae, E. I., Shaibu, S., Corless, I. B., et al. (2016). Building trust and relationships between patients and providers: An essential complement to health literacy in HIV care. Journal of the Association of Nurses in AIDS Care, 27(5), 574-584. https://doi.org/10.1016/j.jana.2016.03. 001.

Deml, M. J., Jafflin, K., Merten, S., Huber, B., Buhl, A., Frau, E., Mettraux, V., Sonderegger, J., Kliem, P., Cattalani, R., Krüerke, D., Pfeiffer, C., Burton-Jeangros, C., \& Tarr, P. E. (2019). Determinants of vaccine hesitancy in Switzerland: Study protocol of a mixed-methods national research programme. BMJ Open, 9(11), 1-14. https://doi.org/10.1136/bmjopen-2019-032218.

Dirks, K. T., \& Ferrin, D. L. (2001). The role of trust in organizational settings. Organization Science, 12, 450-467.

Dub'e, E., Gagnon, D., Nickels, E., Jeram, S., \& Schuster, M. (2014). Mapping vaccine hesitancy- Country-specific characteristics of a global phenomenon. Vaccine, 32(49). https://doi.org/10.1016/j. vaccine.2014.09.039.

Dubé, E., Gagnon, D., MacDonald, N. E., Eskola, J., Liang, X., Chaudhuri, M., Dube, E., Gellin, B., Goldstein, S., Larson, H., Manzo, M. L., Reingold, A., Tshering, K., Zhou, Y., Duclos, P., Guirguis, S., Hickler, B., \& Schuster, M. (2015). Strategies intended to address vaccine hesitancy: Review of published reviews. Vaccine, 33(34), 4191-4203. https://doi.org/10.1016/j.vaccine.2015.04.041.
Evans, D. R., Yemeke, T. T., Kiracho, E. E., Mutebi, A., Apolot, R. R., Ssebagereka, A., \& Ozawa, S. (2019). Trust in vaccines and medicines in Uganda. Vaccine, 37(40), 6008-6015. https://doi.org/10. 1016/j.vaccine.2019.07.022.

Fadda, M., Albanese, E., \& Suggs, L. S. (2020). When a COVID-19 vaccine is ready, will we all be ready for it? International Journal of Public Health, 65, 711-712. https://doi.org/10.1007/s00038-02001404-4.

Finn, S., \& O'Fallon, L. (2017). The emergence of environmental health literacy-From its roots to its future potential. Environmental Health Perspectives, 125(4), 495-501. https://doi.org/10.1289/ehp. 1409337.

Frank, K., \& Arim, R. (2020). Canadians 'willingness to get a COVID19 vaccine when one becomes available: What role does trust play? (Issue July).

French, J., Deshpande, S., Evans, W., \& Obregon, R. (2020). Key guidelines in developing a pre-emptive COVID-19 vaccination uptake promotion strategy. International Journal of Environmental Research and Public Health, 17(16), 1-14. https://doi.org/10. 3390/ijerph17165893.

Fritz, M. S., \& Mackinnon, D. P. (2007). Required sample size to detect the mediated effect. Association for Psychological Science, 18(3), 233-239. https://doi.org/10.1111/j.1467-9280.2007.01882.x. Required.

Goggins, K. M., Wallston, K. A., Nwosu, S., Schildcrout, J. S., Castel, L., \& Kripalani, S. (2014). Health literacy, numeracy, and other characteristics associated with hospitalized patients' preferences for involvement in decision making. Journal of Health Communication, 19, 29-43. https://doi.org/10.1080/10810730.2014.938841.

Guo, S., Naccarella, L., Yu, X., Armstrong, R., Browne, G., Shi, Y., \& Davis, E. (2020). Health literacy and its mediating role in predicting health behaviors among Chinese secondary students. Asia-Pacific Journal of Public Health., 33, 76-83. https://doi.org/10.1177/ 1010539520980926.

Harrison, E. A., \& Wu, J. W. (2020). Vaccine confidence in the time of COVID-19. European Journal of Epidemiology, 35(4), 325-330. https://doi.org/10.1007/s10654-020-00634-3.

Jarrett, C., Wilson, R., O’Leary, M., \& Eckersberger, E. L. H. (2015a). SAGE Working Group on Vaccine Hesitancy. Strategies for addressing vaccine hesitancy - A systematic review. Vaccine, 33(34), 4180-4190. https://doi.org/10.1016/j.vaccine.2015.04.040.

Jarrett, C., Wilson, R., O’Leary, M., Eckersberger, E., Larson, H. J., Eskola, J., Liang, X., Chaudhuri, M., Dube, E., Gellin, B., Goldstein, S., Larson, H., MacDonald, N., Manzo, M. L., Reingold, A., Tshering, K., Zhou, Y., Duclos, P., Guirguis, S., et al. (2015b). Strategies for addressing vaccine hesitancy - a systematic review. Vaccine, 33(34), 4180-4190. https://doi.org/10. 1016/j.vaccine.2015.04.040.

Karras, J., Dubé, E., Danchin, M., Kaufman, J., \& Seale, H. (2019). A scoping review examining the availability of dialogue-based resources to support healthcare providers engagement with vaccine hesitant individuals. In vaccine (Vol. 37, issue 44, pp. 65946600). Elsevier ltd. https://doi.org/10.1016/j.vaccine.2019.09.039.

Kim, J. H. (2019). Multicollinearity and misleading statistical results. Korean Journal of Anesthesiology, 72(6), 558-569. https://doi.org/ 10.4097/kja.19087.

Larson, H., Jarrett, C., Schulz, W., Chaudhuri, M., Zhou, Y., \& Dube, E. (2015). Measuring vaccine hesitancy: The development of a survey tool. Vaccine, 33, 4165-4175.

Le, T. T., Andreadakis, Z., \& Kumar, A. (2020). The COVID-19 vaccine development landscape. Nature Reviews. Drug Discovery, 19(5), 305-306.

Leask, J., Kinnersley, P., Jackson, C., Cheater, F., Bedford, H., \& Rowles, G. (2012). Communicating with parents about vaccination: A framework for health professionals. In BMC Pediatrics (Vol. 12, 
issue 1, p. 154). BioMed Central Ltd. https://doi.org/10.1186/14712431-12-154.

Levin, D. Z. (1999). Transferring knowledge within the organization in the $R \& D$ arena. Unpublished doctoral dissertation, .

Levin, Daniel Z., \& Cross, R. (2004). The strength of weak ties you can trust: The mediating role of trust in effective knowledge transfer. In management science (Vol. 50, issue 11, pp. 1477-1490). INFORMS. https://doi.org/10.1287/mnsc.1030.0136.

Li, Q., Tang, B., Bragazzi, N. L., Xiao, Y., \& Wu, J. (2020). Modeling the impact of mass influenza vaccination and public health interventions on COVID-19 epidemics with limited detection capability. Mathematical Biosciences, 325(May), 108378. https://doi.org/10. 1016/j.mbs.2020.108378.

Lorini, C., Santomauro, F., Donzellini, M., Capecchi, L., Bechini, A., Boccalini, S., Bonanni, P., \& Bonaccorsi, G. (2018). Health literacy and vaccination: A systematic review. Human Vaccines and Immunotherapeutics, 14(2), 478-488. https://doi.org/10.1080/ 21645515.2017.1392423.

Mackert, M., Champlin, S. E., Pasch, K. E., \& Weiss, B. D. (2013). Understanding health literacy measurement through eye tracking. Journal of Health Communication, 18(SUPPL. 1), 185-196. https://doi.org/10.1080/10810730.2013.825666.

Magadmi, R. M., \& Fatemah, O. K. (2020). Beliefs and barriers associated with COVID-19 vaccination among the general population in Saudi Arabia. Research Square.

Magasi, S., Durkin, E., Wolf, M. S., \& Deutsch, A. (2009). Rehabilitation consumers' use and understanding of quality information: A health literacy perspective. Archives of Physical Medicine and Rehabilitation, 90(2), 206-212.

Mancuso, C., \& Rincon, M. (2006). Asthma patients' assessments of health care and medical decision making: The role of health literacy. Journal of Asthma, 43(1), 41-44. https://doi.org/10.1080/ 02770900500447052.

Mayer, R. C., Davis, J. H., \& Schoorman, F. D. (1995). An integration model of organizational trust. Acad. Management Rev., 20, 709734.

Meppelink, C. S., Smit, E. G., Fransen, M. L., \& Diviani, N. (2019). "I was right about vaccination": Confirmation Bias and health literacy in online health information seeking. Journal of Health Communication, 24(2), 129-140. https://doi.org/10.1080/ 10810730.2019 .1583701 .

Nutbeam, D. (2000). Health literacy as a public goal: A challenge for contemporary health education and communication strategies into the 21st century. Health Promotion International, 15(3), 259-267. https://doi.org/10.1093/heapro/15.3.259.

Palamenghi, L., Barello, S., Boccia, S., \& Graffigna, G. (2020). Mistrust in biomedical research and vaccine hesitancy: The forefront challenge in the battle against COVID-19 in Italy. European Journal of Epidemiology, 35(8), 785-788. https://doi.org/10.1007/s10654020-00675-8.

Pati, S., Mohamad, Z., Cnaan, A., Kavanagh, J., \& Shea, J. A. (2010). Influence of maternal health literacy on child participation in social welfare programs: The Philadelphia experience. American Journal of Public Health, 100(9), 1662-1665. https://doi.org/10.2105/ AJPH.2009.172742.

Revised report of the SAGE Working Group on Vaccine Hesitancy. (2014). Report of the Sage Working Group on Vaccine Hesitancy. https://www.who.int/immunization/sage/meetings/2014/october/1 Report_WORKING_GROUP_vaccine_hesitancy_final.pdf

Rodriguez, N. J. (2016). Vaccine-Hesitant Justifications: "Too Many, Too Soon," Narrative Persuasion, and the Conflation of Expertise. Global Qualitative Nursing Research, 3, 1-10. https://doi.org/10. $1177 / 2333393616663304$
Rose, A., Peters, N., Shea, J. A., \& Armstrong, K. (2004). Development and testing of the health care system distrust scale. Journal of General Internal Medicine, 19(1), 57-63. https://doi.org/10.1111/j. 1525-1497.2004.21146.x.

Shapiro, G. K., Tatar, O., Dube, E., Amsel, R., Knauper, B., Naz, A., Perez, S., \& Rosberger, Z. (2018). The vaccine hesitancy scale: Psychometric properties and validation. Vaccine, 36(5), 660-667. https://doi.org/10.1016/j.vaccine.2017.12.043.

Sherman, S. M., Smith, L. E., Sim, J., Amlôt, R., Cutts, M., Dasch, H., James Rubin, G., \& Sevdalis, N. (2020). COVID-19 vaccination intention in the UK: Results from the COVID-19 Vaccination Acceptability Study (CoVAccS), a nationally representative crosssectional survey. MedRxiv Preprint, 2020(08), 13.20174045. https:// doi.org/10.1101/2020.08.13.20174045.

Sorensen, K. (2013). Health literacy: The neglected European public health disparity. In Faculty of Health, medicine, and life sciences. Maas- tricht University.

Sørensen, K., Van Den Broucke, S., Pelikan, J. M., Fullam, J., Doyle, G., Slonska, Z., Kondilis, B., Stoffels, V., Osborne, R. H., \& Brand, H. (2013). Measuring health literacy in populations: Illuminating the design and development process of the European Health Literacy Survey Questionnaire (HLS-EU-Q). BMC Public Health, 13(1). https://doi.org/10.1186/1471-2458-13-948.

Stormacq, C., Van den Broucke, S., \& Wosinski, J. (2019). Does health literacy mediate the relationship between socioeconomic status and health disparities? Integrative review. Health Promotion International, 34(5), e1-e17. https://doi.org/10.1093/heapro/ day062.

Sun, S., Lin, D., \& Operario, D. (2020). Interest in COVID-19 vaccine trials participation among young adults in China: Willingness, reasons for hesitancy, and demographic and psychosocial determinants. Preprint, 1-24.

Toçi, E., Burazeri, G., Sorensen, K., Jerliu, N., Ramadani, N., Roshi, E., \& Brand, H. (2013). Health literacy and socioeconomic characteristics among older people in transitional Kosovo. British Journal of Medicine and Medical Research, 3(4), 1646-1658. https://doi.org/ 10.9734/bjmmr/2013/3972.

Trueblood, J. S., Sussman, A. B., \& O'Leary, D. (2020). The role of general risk preferences in messaging about COVID-19 vaccine take-up. Preprint, 1-13.

Turhan, Z., Dolu, İ., \& Yalnız Dilcen, H. (2020a). Actions and perspectives towards the Covid-19 candidate vaccines. International Conference on Different Aspects of Health

Wang, X., Zhou, X., Leesa, L., \& Mantwill, S. (2018). The effect of vaccine literacy on parental trust and intention to vaccinate after a major vaccine scandal. Journal of Health Communication, 23(5), 413-421. https://doi.org/10.1080/10810730.2018.1455771.

World Health Organization (WHO). (2015). Vaccine hesitancy: a growing challenge for immunization programmes. Retrieved from: https://www.who.int/news/item/18-08-2015-vaccine-hesitancy-agrowing-challenge-for-immunization-programmes

Yalnız Dilcen, H., Dolu, I., \& Turhan, Z. (2020b). Asi Teredduttu Olcegi Gecerlilik Guvenirlik Calismasi - Validity and Reliability Study of the Vaccine Hesitancy Scale. Uluslararası Anadolu Ebeler Derneği Kongresi, (Sunum Numarasi: SS-107)

Yeșildal, M., Erișen, A., \& Kıraç, R. (2020). Sağlık sistemlerine güvensizlik: bir geçerlilik ve güvenilirlik çalıșması (Health care systems distrust: a validity and reliability study). Uluslararası Sağllk Yönetimi Ve Stratejileri Araştırma Dergisi (International Health Management and Strategies Research Journal), 6(2), 251-259.

Publisher's Note Springer Nature remains neutral with regard to jurisdictional claims in published maps and institutional affiliations. 